\title{
Study on Influences of Large-scale Sports Events on Regional Economy
}

\author{
Qingshan Sun \\ Physical Education Department, Qingdao University of Science and Technology \\ Qingdao 266042, China \\ E-mail: paperqust@163.com
}

Received: June 4, $2011 \quad$ Accepted: June 20, $2011 \quad$ Published: October 1, 2011

doi:10.5539/ass.v7n10p277 URL: http://dx.doi.org/10.5539/ass.v7n10p277

\begin{abstract}
This article summarizes development of large-scale sports events and analyzes positive and negative influences of large-scale sports events on regional economic development. On that basis, the author further proposes such conclusion and suggestions to change the concept and bidding actively for holding the Olympic Games to promote innovation through competition, be established in the future and build up long term effect, etc.
\end{abstract}

Keywords: Sports events, Regional economy, City image

\section{Introduction}

Holding sports events is an effective approach to improving city image and pushing forward urban economic development. Sports events may exert significant influences upon both host cities and the country in which the host cities are located, since sports events can not only furnish leisure and recreation activities, but also play an immeasurable role in re-moulding city image, speeding up urban construction, stimulating economic development of host cities and generating extra tax and development effects of pre-competition and post-competition.

\section{Development of sports events}

As one of the components of human culture, sports events have been generated and developed with economic and social development. In the process of development, sports events are affected and restrained by multiple factors, such as politics and economy, etc, but to a certain extent, they can offer service for politics and economy. For example, Olympic Games is abbreviated as "Olympics", which is a global comprehensive sports meeting that is sponsored by the International Olympic Committee (IOC). Its name originated from Olympia in Greece, and it is held every four years. The ancient Olympic Games was held altogether 293 times from BC 776 to AD 393, and finally was abolished by the Roman Emperor Theodosius under the crime of paganism. In 1894, at the international sports meeting that was held in Paris, the International Olympic Games was set up according to proposal o Coubertin and also it was determined at the meeting to recover the Olympic Games. In 1896, the first modern Olympic Games was held in Athens in Greece, and then different countries all over the world took the turns to hold the Olympic Games. The time duration is 16 days for each Olympic Games held and there are more than 30 major competition items. In 1924, Winter Olympic Games was held for the first time. Habitually, Olympic Games with non-winter competition items are called "Summer Olympic Games" or "Olympics". Ever since the $60 \mathrm{~s}$ and $70 \mathrm{~s}$ in the Twentieth Century, the Olympic Games has found its combination point with the commercial society.

It should be mentioned, the traditional competitive sports concept was a little bit changed after 1992 when the Olympic Games accepted professional athletes, and the former social and cultural activities which emphasized spiritual significance were step by step changed to commercialized activities which emphasized pursuit of interests. Moreover, new technology and new training means have been integrated, which enables performance of all sorts of sports events to take a rapid change and the degree of competition to become more and more fierce and cruel. Therefrom, competitive sports gradually become a sort of activity with enormous consumption (including resources and energy, etc). The Olympic Games gradually becomes a grand occupational skill competition meeting. However, in a society that is led by the market economy, commercialization of sports events will necessarily turn to be the necessary trend of sports for survival and development in the market. 
Demand and supply is an invariable subject in the market economy, and there is no exception to sports events. Transition of sports events is based on those in demand, namely, continuously increasing income and more leisure time. In the mean time, it depends on those for supply, namely, government of all countries and all kinds of international and domestic sports organizations who push forward industrialization and socialization of sports and drive development of related industries. Holding large-scale sports event all over the world can surpass constraints of language, society and race and become a bridge for communication and exchange of all people from the world. The function of modern sports events is enormous, and they are playing an immeasurable role in enlarging employment and foreign exchange earnings, etc.

\section{Influences of large-scale sports events on regional economy}

A general survey of studies on influences of sports events on the economy both at home and abroad, it is discovered that most studies are concentrated on the Olympic Games, and a large majority of scholars hold the viewpoint that influences of sports events on regional economy are enormous, positive and active. Nevertheless, there are also a small minority of scholars who take a negative attitude, such as, Professor Bader. Through his study on sports organizers of the US World Club, he thought that influences of this competition upon the urban economy were not quite obvious. According to the author, any object has two sides, and there is no exception to sports events. Thus, we should not negate the positive effects just due to the negative effects. Likewise, we should not ignore the negative effects just taking into consideration the positive effects. In the following, the author analyzes influences of large-scale sports events on regional economy from four aspects.

\subsection{Influences on urban infrastructure construction}

Holding a large-scale sports event usually requires large scale infrastructure modification and building, since it has to have competition stadium with high specifications and supporting facilities of highly developed traffic and telecommunication, etc. Guangzhou made an investment of 12 billion RMB Yuan for the Ninth National Games in 2001, which was used for urban infrastructure construction and to build the Pearl River Bridge and totally-enclosed city highway and the new international airport, etc. It also made an investment of 5 billion RMB Yuan in environmental protection, which made Guangzhou take an earthshaking change. In addition, in order to successfully hold the Asian Games in 2010, Guangzhou made a total investment of approximately 220 billion RMB Yuan, which was used to make modifications on municipal construction of the city, to do a series of work on afforest and brightening the appearance of the city, to make a lot of improvement on urban environment and facilities, and, meanwhile, to speed up construction of a batch of landmark commercial net sites and increase characteristic tourism resources of "Guangzhou Gourmet paradise" and "Lingnan Pub Street", etc.

\subsection{To enhance the brand image of the city and to attract investment and tourism}

Under the background with fierce market competition, the operation idea that "good wine needs no bush" has lagged behind. Moreover, with development of social economy, the management idea of cities is also taking great changes and is changing from management of cities to marketing of cities. As for a city, perfect infrastructure and perfect functions are just internal factors to promote competitive strength of the city, while to propagandize the city, to market the city and to set up good city brand are the external factors to promote competitive strength of the city. A critical aspect that sports event affects the competitive strength of the host city is that it can propagandize the city, enlarge influential power of the city and enhance the image of the city. Sports event propagandizes a city by means of the following approaches: large amount of media reports, effect of word of mouth of tourists who directly watch a competition event, direct advertising and different sports events of the city, a series of work on promoting the cities by organizers or the city government by combining the sports events and image dissemination by indirect insiders, etc. The investment environment of the country or the city where the Olympic Games is held may be manifested from a direct or indirect perspective through media of sports events. For example, Tokyo in Japan and Barcelona in Spain have been known to the whole world for they have successfully held the Olympic Games, which has driven significant changes in terms of economy and politics in the country.

In addition, modern large-scale sports stadium also plays a decisive role in moulding the city image, and especially magnificent, novelty and unconventional sports stadium might become an indispensable bright scenery of a city. For instance, "Bird's Nest" and "Water Cube" during the Beijing Olympic Games in 2008 are typical examples, which have become symbolic buildings in Beijing and lightspots of the city image and which are also the first choice for scenery spot by foreign tourists.

\subsection{To facilitate development of relevant industries}

Large-scale sports event may greatly stimulate development of the secondary industry and the tertiary industry, especially those industries that are closely related with sports economy, such as, tourism, commercial catering 
industry, social service industry and cultural industry, etc., on which sports events have obvious driving and stimulating effects. Holding a sports event requires new building of a large number of stadiums and hotels, which need working staff and service personnel, which, in turn, means offering employment opportunities and alleviating more increasingly austere employment pressure. According to statistics, Sydney Olympic Games in 2000 brought employment opportunities for a hundred thousand people. The success of bidding for Beijing Olympic Games in 2008 not only stimulated west-east gas transportation, west-east natural gas transmission and west-east electricity transmission, but also accelerated western development and construction in China. The international marathon competition that was held in Xiamen invited a multitude of competitors and tens of thousands of tourists from over the world, which enabled quite a large number of catering units to realize an operation income growth of as high as $35 \%$, some hotels to be fully accommodated and all supermarkets to have a greatly increasing sales amount. Furthermore, the Beijing Olympic Games in 2008 pushed forward commercial tourism, finance and insurance in Beijing to reach a new level and the expos and information service to get greatly developed. By the end of the year 2008, the Olympic Games had realized an appreciation of 390 billion RMB Yuan and new and high tech industries had realized an appreciation of 60 billion RMB Yuan. In addition, holding a sports event can also promote internal structural adjustment and optimization of the industries, marketing means, service technology, operation ideas and so on will be geared to the international world step by step, service quality and level will get obviously improved, such modern service industries as information consulting industry and modern logistics will be accelerated in development, the industrial scale will be rapidly expanded and ratio of industries will be obviously increased.

\subsection{Negative effects on a host city}

At the time when large scale sports events have positive effects on a host city, there are also some negative effects. The first negative effect is the problem of traffic jam. According to the "survey of public evaluation on traffic condition of Guangzhou" that was promulgated on March 2, 2008, there were 35.9\% Guangzhou citizens who were not satisfied with traffic in Guangzhou. Thus, in the forthcoming Asian Games to be held in Guangzhou in 2010 may also greatly add weight to pressure of traffic and transportation in Guangzhou in that at the time when it brings convenience to citizens in Guangzhou, it also brings inconvenience to tourists. The second negative effect is the problem of increasing price of commodities. During the sports events, the comprehensive consumption capacity would be greatly increased, but the enterprises would closely grasp the fleeting market opportunity to enhance the price of relevant products. However, the double-edged sword of price will also greatly add weight to the living burden of local residents at the time when it brings generous profits to enterprises, which might reduce the life quality of local residents. The third negative effect is damage to the environment. During the sports events, when quite a large number of tourists watch the competition, it is quite probable that they go sighting to the tourist attractions of the host city. However, the volume of the scenery is limited, so rapid growth in number of tourists may increase the burden of the scenery and may, meanwhile, bring about serious threats to resources of the host city. In addition, during the sports events, it's inevitable that tourists will generate house refuse and frequent use of city traffic will also necessarily cause a lot of noise and exhaust gas, which may give rise to great damage to the ecological environment of the city. For instance, during the $16^{\text {th }}$ Winter Olympic Games that was held in Albertville in France, an area of 300,000 hectares of forests got destroyed and quite a lot of living beings thus lost the environment they depended on and were reduced rapidly, which gave rise to serious ecological crisis. The last negative effect is that the utilization rate of sports stadiums is low and the problem of low utilization rate of a large number of sports stadiums happened in a large number of countries after the sports events were over. A large number of sports facilities and stadiums that were built with a huge amount of funds by the host cities were left unused and even abandoned. What's more, some stadiums may be dismantled after the sports events and out-dated building materials may be disposed of. Idleness of sports facilities is a general phenomenon after a multitude of large scale international sports events. Furthermore, idleness and expenses on maintenance of a large number of sports facilities that are left after a sports event were also a tough problem.

\section{Conclusions and suggestions}

\subsection{To change the concept, actively bid for holding the Olympic Games and to facilitate innovation through competition}

Holding a large scale sports event is something positive to promote overall development of a city. Thus, all from the government to individuals ought to have sufficient knowledge in the promoting effects of sports events on political and economic development of the city and the region and in relationship between holding a large scale sports event and regional economic development. We have to change the out-dated concept, get free from the thought of holding a sports competition by wasting man power and money. All should come to full realization 
that a large sports event is a powerful motive to push forward economic development and grasp all opportunities to actively bid for holding a large scale sports event. Besides, as a tertiary industry, sports industry also has to change the traditional sports concept, get geared to the market economy and make competitive sports to walk towards the path of socialization, industrialization, professionalization and commercialization. On one hand, sports events can bring spiritual enjoyment to people to appreciate sports, and, on the other hand, can edify the team cooperation and tenacious fighting consciousness of all competing parties, implant the new concept of marketization to the traditional sports and make people recognize sports competition, which may help stimulate people to devote themselves to construction of marketization of sports industry. Therefore, in holding a sports event, it is necessary to pay attention to get mastery of the direction of public opinions, carry forward the spirit of competition, surpassing and fairness in sports events, and make people get positively "attacked", recognize greatly the tenacious fighting spirit for sports and willing to escalate this spirit into the career of national construction.

\subsection{To be established in the future and to build long term effect}

Sustainable development is the topic in contemporary social development. However, in the process when social economy is continuously growing, lots of people use "green industry" to figuratively refer to the sports industry. This, just right, verifies connotation of the sports industry as a newly born industry with sustainable development in the process of contemporary social and economic development and social consumption. Furthermore, considering influences of the sports industry on social consumption means and methods, it also has extremely powerful market potential. Thus, as for a host city, it should not see a sports event as an event for one time. Instead, in order for a host city to drive development of all aspects of the city through the sports event, it has to hold a high level sports event, which may not have general applicability. In addition, the host city has to be on guard against the phenomenon of "post-competition lassitude", which is also a kind of phenomenon that has been put forward in a lot of previous literature. For example, after the Sydney Olympic Games in 2000, the city of Sydney undertook a post-competition lassitude for approximately three years.

\subsection{To reform the mechanism and to set up correct ideas}

Now that sports has been deemed as a kind of industry, its establishment and operation ought to be based on system of modern enterprises, namely, separation of government affairs, government and enterprises and government and the public. As for a sports industry management institution, it also has to strengthen social management and set up industrial management organs and departments, which is the precondition to really enter the society and the market. Likewise, in the condition of market economy, resolving the problem of funds for the sports industry should also be finished through the market, since only if the sports are brought to the market economy and only if the industrialization is realized, can the sports industry obtain vitality and vigor and can be development continuously and sustainably. Samaranch, the International Olympic Committee Chairman, has ever said, "Without commercial assistance, the Olympic Games might go towards death". Thus, a sports event, which is operated as an industry, not only has to provide all sorts of operation service to satisfy the social demands of sports events, but also has to primarily apply the enormous economic benefits which have been obtained through the sports events to improvement of sports facilities, current development and development in the future and consolidate solid economic backup force for the industry of sports.

\subsection{To improve policies, strengthen service and provide high quality environment}

A local host government should be established in the future and in the overall situation, build a relaxed sports event competition environment, combine innovatively large scale sports events with local economy in an organic way, resort to all sorts of policies and services of tax, finance and foreign trade and regard a large scale sports event as a means to collect talents and attract capital.

\section{References}

Shi, Li. (2006). Discussion on Sports Events and Social and Economic Development. China Economist, (6).

Tang, Dongfang \& Zhang, Jianwu. (2002). Influence of Large-Scale Sports Games on Local Economic Development. Sport Science, (5).

Tang, Xiaotong. (2007). The Spread Effect of Large Scale International Sports Competition Events on social development. Journal of Guangzhou Sport University, (1).

Yang, Yue. (2005). Influences of the 2008 Olympic Games on Economy in Beijing. Sport Science, (8).

Zhou, Wenyan. (2008). Influences of Sports Events on Economic Development of a Host City. Industry Observe, (8). 